\title{
A Multicenter, Randomized Trial of Treatment for Mild Gestational Diabetes
}

\author{
Mark B. Landon, M.D. ${ }^{1}$, Catherine Y. Spong, M.D. ${ }^{2}$, Elizabeth Thom, Ph.D. ${ }^{3}$, Marshall W. \\ Carpenter, M.D. ${ }^{4}$, Susan M. Ramin, M.D. ${ }^{5}$, Brian Casey, M.D. 6 , Ronald J. Wapner, M.D. ${ }^{7}$, \\ Michael W. Varner, M.D. ${ }^{8}$, Dwight J. Rouse, M.D. ${ }^{9}$, John M. Thorp Jr., M.D. ${ }^{10}$, Anthony \\ Sciscione, D.O. ${ }^{11}$, Patrick Catalano, M.D. ${ }^{12}$, Margaret Harper, M.D. ${ }^{13}$, George Saade, M.D. \\ ${ }^{14}$, Kristine Y. Lain, M.D. ${ }^{15}$, Yoram Sorokin, M.D. ${ }^{16}$, Alan M. Peaceman, M.D. ${ }^{17}$, Jorge E. \\ Tolosa, M.D., M.S.C.E. ${ }^{18}$, and Garland B. Anderson, M.D. ${ }^{14}$ for the Eunice Kennedy Shriver \\ National Institute of Child Health and Human Development Maternal-Fetal Medicine Units \\ Network*
}

${ }^{1}$ Department of Obstetrics and Gynecology at Ohio State University, Columbus ${ }^{2}$ Eunice Kennedy Shriver National Institute of Child Health and Human Development, Bethesda, MD ${ }^{3}$ George Washington University Biostatistics Center, Washington, DC ${ }^{4}$ Departments of Obstetrics and Gynecology at Brown University, Providence, $\mathrm{RI}^{5}$ University of Texas Health Science Center at Houston, Houston ${ }^{6}$ University of Texas South-western Medical Center, Dallas ${ }^{7}$ Columbia University, New York ${ }^{8}$ University of Utah, Salt Lake City ${ }^{9}$ University of Alabama at Birmingham, Birmingham ${ }^{10}$ University of North Carolina, Chapel Hill ${ }^{11}$ Drexel University, Philadelphia ${ }^{12}$ Case Western Reserve University, Cleveland ${ }^{13}$ Wake Forest University Health Sciences, Winston-Salem, NC ${ }^{14}$ University of Texas Medical Branch, Galveston ${ }^{15}$ University of Pittsburgh, Pittsburgh ${ }^{16}$ Wayne State University, Detroit ${ }^{17}$ Northwestern University, Chicago ${ }^{18}$ Oregon Health and Science University, Portland

\section{Abstract}

BACKGROUND-It is uncertain whether treatment of mild gestational diabetes mellitus improves pregnancy outcomes.

\begin{abstract}
METHODS-Women who were in the 24th to 31st week of gestation and who met the criteria for mild gestational diabetes mellitus (i.e., an abnormal result on an oral glucose-tolerance test but a fasting glucose level below $95 \mathrm{mg}$ per deciliter [ $5.3 \mathrm{mmol}$ per liter]) were randomly assigned to usual prenatal care (control group) or dietary intervention, self-monitoring of blood glucose, and insulin therapy, if necessary (treatment group). The primary outcome was a composite of stillbirth or perinatal death and neonatal complications, including hyperbilirubinemia, hypoglycemia, hyperinsulinemia, and birth trauma.
\end{abstract}

\begin{abstract}
RESULTS - A total of 958 women were randomly assigned to a study group - 485 to the treatment group and 473 to the control group. We observed no significant difference between groups in the frequency of the composite outcome (32.4\% and $37.0 \%$ in the treatment and control groups, respectively; $\mathrm{P}=0.14$ ). There were no perinatal deaths. However, there were significant reductions with treatment as compared with usual care in several prespecified secondary outcomes, including
\end{abstract}

\footnotetext{
Address reprint requests to Dr. Landon at mark.landon@osumc.edu.

The other members of the Eunice Kennedy Shriver National Institute of Child Health and Human Development (NICHD) MaternalFetal Medicine Units Network are listed in the Appendix.

Presented in part at the 29th annual meeting of the Society for Maternal-Fetal Medicine, San Diego, CA, January 26-31, 2009.

No potential conflict of interest relevant to this article was reported.
} 
mean birth weight (3302 vs. 3408 g), neonatal fat mass (427 vs. 464 g), the frequency of large-forgestational-age infants ( $7.1 \%$ vs. $14.5 \%)$, birth weight greater than $4000 \mathrm{~g}(5.9 \%$ vs. $14.3 \%)$, shoulder dystocia ( $1.5 \%$ vs. $4.0 \%$ ), and cesarean delivery ( $26.9 \%$ vs. $33.8 \%)$. Treatment of gestational diabetes mellitus, as compared with usual care, was also associated with reduced rates of preeclampsia and gestational hypertension (combined rates for the two conditions, $8.6 \%$ vs. $13.6 \%$; $=0.01$ ).

CONCLUSIONS-Although treatment of mild gestational diabetes mellitus did not significantly reduce the frequency of a composite outcome that included stillbirth or perinatal death and several neonatal complications, it did reduce the risks of fetal overgrowth, shoulder dystocia, cesarean delivery, and hypertensive disorders.

Gestational diabetes mellitus is defined as glucose intolerance that first occurs or is first identified during pregnancy. ${ }^{1}$ The frequency of this condition is rising in the United States and occurs in 1 to $14 \%$ of all pregnancies, depending on varying characteristics of the population.

2 More than 40 years ago, O'Sullivan and Mahan developed glucose-tolerance-test criteria for the diagnosis of gestational diabetes mellitus. ${ }^{3}$ The diagnostic thresholds that they developed were based on the subsequent development of adult-onset diabetes and were not predicated on any association between carbohydrate intolerance discovered during gestation and adverse pregnancy outcomes.

Although gestational diabetes mellitus is a recognized marker for an increased risk of subsequent diabetes, its clinical significance with respect to various adverse pregnancy outcomes has been uncertain. ${ }^{2,4}$ Women with gestational diabetes who have very elevated fasting blood glucose levels appear to be at an increased risk for fetal macrosomia and perinatal complications if treatment is not provide, ${ }^{5}$ but the association of milder forms of gestational diabetes with such outcomes has been unclear. The recent Hyperglycemia and Adverse Pregnancy Outcome (HAPO) study, however, described a strong continuous association between maternal glucose concentrations and increasing birth weight, cord-blood serum Cpeptide levels, and other markers of perinatal complications, even at glucose concentrations below those that are usually diagnostic of gestational diabetes mellitus. ${ }^{6}$

Several professional organizations have recommended screening for gestational diabetes mellitus for most pregnant women despite little evidence that the identification and treatment of mild carbohydrate intolerance during pregnancy confer a benefit. ${ }^{1,7}$ The Australian Carbohydrate Intolerance Study in Pregnant Women (ACHOIS), a large, randomized trial of treatment for gestational diabetes mellitus, concluded that treatment reduces serious perinatal complications and may also improve health-related quality of life. ${ }^{8}$ Despite these findings, the 2008 guidelines of the U.S. Preventive Services Task Force again concluded that current evidence is insufficient to assess the balance between benefit and harm with respect to the screening and treatment of gestational diabetes mellitus. ${ }^{9}$ We performed the present randomized trial to determine whether treatment of women with mild gestational diabetes mellitus reduces perinatal and obstetrical complications.

\section{METHODS STUDY DESIGN}

Women were invited to participate in this study if, between 24 weeks 0 days and 30 weeks 6 days of gestation, they had a blood glucose concentration between 135 and $200 \mathrm{mg}$ per deciliter (between 7.5 and $11.1 \mathrm{mmol}$ per liter) 1 hour after a 50-g glucose loading test. Women were excluded if they had preexisting diabetes, an abnormal result on a glucose screening test before 24 weeks of gestation, prior gestational diabetes, a history of stillbirth, multifetal gestation, asthma, or chronic hypertension; if they were taking corticosteroids; if there was a known fetal anomaly; or if imminent or preterm delivery was likely because of maternal disease or fetal 
conditions. All the women who pa rticipated in the study provided written informed consent. The study was approved by the human subjects committee at each participating center.

After an overnight fast, eligible women completed a blinded 3-hour 100-g oral glucosetolerance test. Samples were analyzed at a central laboratory, and results were forwarded to the data coordinating center. Mild gestational diabetes mellitus was defined as a fasting glucose level of less than $95 \mathrm{mg}$ per deciliter (5.3 mmol per liter) and two or three timed glucose measurements that exceeded established thresholds: 1-hour, $180 \mathrm{mg}$ per deciliter $(10.0 \mathrm{mmol}$ per liter); 2-hour, $155 \mathrm{mg}$ per deciliter ( $8.6 \mathrm{mmol}$ per liter); and 3-hour, $140 \mathrm{mg}$ per deciliter ( $7.8 \mathrm{mmol}$ per liter). ${ }^{10}$ Women who met these criteria were randomly assigned by the coordinating center, with the use of the simple urn method, ${ }^{11}$ stratified by clinical center. The urn method minimizes the degree of imbalance in the number of patients assigned to each group by increasing the probability of a patient's assignment to the group that has previously been selected least often. Women were assigned to receive either formal nutritional counseling and diet therapy, ${ }^{12}$ along with insulin if required (treatment group) or usual prenatal care (control group). In addition, a cohort of women who had a positive result on the $50 \mathrm{-g}$ glucose loading test but a normal result on a subsequent oral glucose-tolerance test and who were matched with the study cohort according to race and body-mass index (the weight in kilograms divided by the square of the height in meters), dichotomized as less than 27 or 27 or more, were enrolled by the data coordinating center in the group that received usual prenatal care. By including this group of women who did not have gestational diabetes mellitus, the patients, their caregivers, and the study staff were unaware of whether women in the control group met the criteria for the diagnosis of mild gestational diabetes mellitus. Women with a fasting glucose level of 95 mg per deciliter or more on the diagnostic oral glucose-tolerance test were excluded from the study, and their condition was made known to their health care providers.

Ultrasonography was performed in all subjects before the oral glucose-tolerance test to confirm the gestational age. Women who were receiving treatment performed daily self-monitoring of their blood glucose (fasting and 2-hour postprandial measurements) with the use of a portable memory-based reflectance meter. Insulin was prescribed if the majority of fasting values or postprandial values between study visits were elevated (fasting glucose level, $\geq 95 \mathrm{mg}$ per deciliter or 2-hour postprandial glucose level, $\geq 120 \mathrm{mg}$ per deciliter [6.7 mmol per liter]). If, during a prenatal visit, there was a clinical suspicion of hyperglycemia in a patient who was in the control group, the blood glucose level could be measured at the discretion of the provider. If a random blood glucose level of $160 \mathrm{mg}$ per deciliter $(8.9 \mathrm{mmol}$ per liter) or more or a fasting glucose level of $95 \mathrm{mg}$ per deciliter or more was detected, the patient's caregiver initiated treatment and notified the local principal investigator and study personnel.

Nonstress testing, biophysical profile testing, and ultrasonography to assess fetal growth were not performed routinely in the treatment group but were reserved for standard obstetrical indications. However, all the women who were enrolled in the study were instructed regarding the daily assessment of fetal activity. ${ }^{13}$ If delivery was not the result of spontaneous labor, the rationale for the timing and method of delivery was documented.

\section{STUDY OUTCOMES}

The primary study out come was a composite outcome that included perinatal mortality (stillbirth or neonatal death) and complications that have been associated with maternal hyperglycemia: hypoglycemia, hyperbilirubinemia, neonatal hyperinsulinemia, and birth trauma. Cord blood was collected and forwarded to a central laboratory for determination of the C-peptide level. Hyperinsulinemia was defined as a cord-blood C-peptide level greater than the 95 th percentile (i.e., greater than $1.77 \mathrm{ng}$ per milliliter) as determined from an unselected obstetrical population of women in the Maternal-Fetal Medicine Units Network of the Eunice Kennedy Shriver National Institute of Child Health and Human Development. Neonatal blood 
for the determination of glucose level was collected with in 2 hours after birth and before feeding; hypoglycemia was defined as a glucose value of less than $35 \mathrm{mg}$ per deciliter (1.9 mmol per liter). ${ }^{14}$ Serum bilirubin was determined between 16 and 36 hours after birth. A value greater than the 95th percentile for any given point after birth was considered to be an elevated level. ${ }^{15}$ Birth trauma was defined as brachial plexus palsy or clavicular, humeral, or skull fracture.

Secondary prespecified neonatal outcome measures included birth weight greater than 4000 $\mathrm{g}$, large size for gestational age (defined as birth weight above the 90th percentile), small size for gestational age (birth weight below the 10th percentile), ${ }^{16}$ admission to the neonatal intensive care unit, and the respiratory distress syndrome. Shortly after the infant's birth, trained research staff measured the infant's length, head and upper mid-arm circumferences, and flank skinfold. Neonatal fat mass was calculated according to the technique of Catalano et al. ${ }^{17}$

Secondary maternal outcomes included weight gain from the time of enrollment to delivery, gestational hypertension, preeclampsia, cesarean delivery, labor induction, and shoulder dystocia. Gestational hypertension was defined as a systolic pressure of $140 \mathrm{~mm} \mathrm{Hg}$ or more or a diastolic pressure of $90 \mathrm{~mm} \mathrm{Hg}$ or more on two occasions at least 4 hours apart, or one elevated blood-pressure value subsequently treated with medication. Preeclampsia was defined as an elevation in blood pressure (according to the definition of gestational hypertension) together with proteinuria (300 $\mathrm{mg}$ of protein or more in a 24-hour urine collection or a result of $2+$ or greater on a dipstick test when a 24-hour collection was not available). Elevated blood pressure with either elevated liver enzyme levels (aspartate aminotransferase level $\geq 70 \mathrm{U}$ per liter) or thrombocytopenia (platelet count $<100,000$ per cubic millimeter) was also diagnosed as preeclampsia. Shoulder dystocia was defined clinically, and the providers were required to document the maneuvers that were specifically used to release the fetal shoulders.

Trained study personnel collected data on all the women in the treatment group at the time of the study visits. The records of all enrolled women and their infants were reviewed at the time of their discharge from the hospital, and information regarding antepartum, intrapartum, and post-delivery complications was recorded. All cases of hypertensive disorders and shoulder dystocia underwent masked central review by two of the authors to ensure that the diagnoses were accurate.

\section{STATISTICAL ANALYSIS}

We reviewed the literature to determine the frequency of each component of the composite outcome among women with gestational diabetes mellitus who were not treated for the condition and among those who were treated. It was assumed that in the group that did not receive treatment for mild gestational diabetes mellitus, the rate of perinatal death, hypoglycemia, hyperbilirubinemia, hyperinsulinemia (C-peptide level above the 95th percentile), or birth trauma would be 20 to $30 \% \cdot{ }^{18-23}$ Assuming a composite outcome rate in the control group of $25 \%$, we calculated that with a sample size of 950 (475 per group), the study would have at least $80 \%$ power to show a $30 \%$ difference in the composite outcome with treatment, with a type I error of 5\% (two-sided). This sample size also provided more than $85 \%$ power to show a reduction of 30\% in the rate of both large-for-gestational age infants (birth weight >90th percentile) and infants with birth weight greater than $4000 \mathrm{~g} .{ }^{24}$

The primary analysis of the clinical trial was conducted according to the intention-to-treat principle. The chi-square test or Fisher's exact test was used to compare categorical variables, and the Wilcoxon rank-sum test was used to compare continuous variables.

During the course of the trial, an external data and safety monitoring committee periodically reviewed the trial results. The group sequential method was used to characterize the rate at 
which the type I error was spent; the chosen spending function was the Lan-DeMets generalization of the O'Brien-Fleming boundary. ${ }^{25}$ Four interim analyses were performed; in the final analysis of the primary outcome, two-tailed $P$ values of less than 0.032 were considered to indicate statistical significance. For this reason, $97 \%$ confidence intervals were used for relative risks.

\section{RESULTS STUDY POPULATION}

From October 2002 through mid-November 2007, we identified 19,665 women who had an abnormal result on a glucose loading test, of whom 10,989 met the inclusion criteria; 7381 consented to undergo a blinded 3-hour oral glucose-tolerance test and to consider enrollment in the randomized trial. A total of 1889 of these women were enrolled; 485 women with mild gestational diabetes mellitus were assigned to the study treatment, and 473 women with mild gestational diabetes mellitus were assigned to receive usual prenatal care. The average time from the performance of the oral glucose-tolerance test to randomization was 4.2 days. An additional 931 women with normal results on the oral glucose-tolerance test were included in the group that received usual prenatal care, to mask the status of the control group (Fig. 1).

The baseline characteristics of the 958 women who were randomly assigned to a study group are shown in Table 1. There were no significant differences in demographic variables or results of the oral glucose-tolerance test between the women in the treatment group and those in the control group.

\section{PERINATAL AND NEONATAL OUTCOMES}

We observed no significant difference between the treatment group and the control group in the frequency of the composite primary perinatal outcome (32.4\% and $37.0 \%$, respectively; relative risk, $0.87 ; 97 \%$ confidence interval $[\mathrm{CI}], 0.72$ to $1.07 ; \mathrm{P}=0.14$ ) (Table 2). There were no perinatal deaths in either group. The individual rates of neonatal hypoglycemia, hyperbilirubinemia, birth trauma, and elevated cord-blood C-peptide level did not differ significantly between the two groups. Adjustment for the baseline reported consumption of any alcohol did not materially affect the relative risk for the primary outcome (relative risk with treatment, $0.88 ; 97 \% \mathrm{CI}, 0.72$ to $1.07 ; \mathrm{P}=0.16$ ). The frequency of intravenous glucose administration in the newborn did not differ significantly between groups.

The mean birth weight and neonatal fat mass, as well as the frequency of large-for-gestational age infants and of infants with a birth weight of $4000 \mathrm{~g}$ or greater, were significantly reduced in the treatment group as compared with the control group. In contrast, the frequency of smallfor-gestational age infants and the frequency of admission to the neonatal intensive care unit did not differ significantly between the groups (Table 3 ).

\section{MATERNAL OUTCOMES}

The rates of labor induction were similar between the treatment and control groups; however, cesarean delivery was significantly less common among women in the treatment group than among women in the control group (26.9\% vs. $33.8 \%, \mathrm{P}=0.02)$ (Table 4). After excluding cases of abnormal presentation, placenta previa, oligohydramnios, and previous cesarean delivery, the cesarean delivery rate remained lower in the treatment group than in the control group $(13.0 \%$ vs. $19.7 \%, \mathrm{P}=0.01)$. The treatment group had a significantly lower frequency of shoulder dystocia $(\mathrm{P}=0.02)$ and preeclampsia or gestational hypertension $(\mathrm{P}=0.01)$ (Table 4). 
After enrollment, women in the treatment group attended an average of seven prenatal visits, as compared with an average of five attended by women in the control group $(\mathrm{P}<0.001)$. Both the body-mass index at delivery and weight gain from enrollment to delivery were lower among women in the treatment group than among those in the control group (Table 4). A total of 37 women in the treatment group required insulin therapy, as compared with 2 in the control group. Data on maternal glucose levels from women in the treatment group indicated that target glycemic thresholds were achieved (Table 5).

\section{DISCUSSION}

This randomized trial showed that although treatment of mild gestational diabetes mellitus did not reduce the frequency of the composite primary perinatal outcome, it did lower the risks of fetal overgrowth, shoulder dystocia, cesarean delivery, and preeclampsia. Overall, consistent with findings from the ACHOIS trial, the findings from our trial confirm a modest benefit from the identification and treatment of women with mild carbohydrate intolerance during pregnancy. ${ }^{8}$ The ACHOIS trial, however, included an ethnically homogeneous group of women who had a greater degree of hyperglycemia than that in our more diverse study population. In addition, we used a 100-g diagnostic oral glucose-tolerance test, whereas a 75$\mathrm{g}$ oral glucose-tolerance test was used in the ACHOIS trial. The ACHOIS trial included a health status survey that showed that there were lower rates of postpartum depression in the intervention group, whereas we did not assess quality-of-life measures.

Our composite primary outcome included perinatal mortality (stillbirth or neonatal death) and complications that have been linked to maternal carbohydrate intolerance: neonatal hypoglycemia, hyperbilirubinemia, and birth trauma. The results of the ACHOIS trial showed that treatment did not reduce the rates of symptomatic neonatal hypoglycemia or jaundice requiring phototherapy ${ }^{8}$ The lack of treatment effect in reducing metabolic abnormalities of the newborn in our study as well as in the ACHOIS trial may be due in part to the fact that these adverse outcomes are most consistently associated with more severe glucose elevations than those that were present in these two study populations. The results from the HAPO study suggested that a threshold for an increased risk of clinical neonatal hypoglycemia may not be $\underset{6}{a}$ apparent until fasting maternal glucose levels exceed $100 \mathrm{mg}$ per deciliter (5.6 mmol per liter).

Associations among macrosomia, shoulder dystocia, and the increased risk of brachial plexus injury in the offspring of women with diabetes are well documented. ${ }^{26}$ Consistent with the results of our trial, the ACHOIS trial also showed a reduction in the rate of shoulder dystocia when women with mild gestational diabetes mellitus received treatment (1\%, vs. $3 \%$ in the untreated group). ${ }^{8}$ However, both trials lacked sufficient power to detect significant differences in uncommon adverse outcomes such as injury to the brachial plexus. Increased birth weight and neonatal fat mass may have long-term health implications for the offspring of mothers with gestational diabetes mellitus, including an increased risk of impaired glucose tolerance and childhood obesity. ${ }^{27,28}$ Long-term follow-up studies are needed to determine whether treatment of gestational diabetes mellitus can reduce the risk of these complications.

The diagnosis of gestational diabetes mellitus, or the knowledge that it is present, has been reported to be associated with an increase in several adverse maternal outcomes. ${ }^{29}$ Rates of cesarean delivery have been consistently higher in pregnancies in which gestational diabetes mellitus has been diagnosed. ${ }^{24,30}$ Naylor and colleagues suggested that simply the recognition that the mother has gestational diabetes mellitus may lead to a lower threshold for operative delivery, thus mitigating the potential benefits of treatment in reducing fetal overgrowth. ${ }^{24} \mathrm{We}$ found that there was a significant reduction in the rate of cesarean delivery among the women who were treated for mild gestational diabetes mellitus, as compared with the rate among the 
women in the control group, and a rate of labor induction that was similar in the two groups. The extent to which a reduction in fetal size and in the frequency of large-for-gestational-age infants as a result of treatment may have contributed to the lower rate of cesarean deliveries is unknown. Labor induction and cesarean delivery may be less commonly performed in academic medical centers, including the centers that participated in this study.

Insulin resistance, a characteristic of gestational diabetes mellitus, has been associated with the development of preeclampsia. ${ }^{31}$ The HAPO study showed a continuous linear association between the results of glucose-tolerance tests and rates of preeclampsia. ${ }^{6}$ Hypertensive disorders of pregnancy are associated with an increased rate of maternal complications and are a major contributor to preterm delivery among women with gestational diabetes mellitus. ${ }^{30}$ Consistent with findings from the ACHOIS trial, ${ }^{8}$ we found a significant reduction in the rates of preeclampsia among women who received treatment for gestational diabetes mellitus. The overall rate of preeclampsia in our study was substantially lower than that in the ACHOIS study, which is probably explained by our use of more stringent diagnostic criteria.

In contrast with previous randomized trials involving women with gestational diabetes mellitus, we verified compliance with glycemic monitoring and documented whether target glucose thresholds were achieved. We did not disclose the results of oral glucose-tolerance tests to caregivers or subjects in the control group in order to minimize the likelihood of selftreatment, which has been a limitation in pilot studies of treatment of gestational diabetes mellitus. ${ }^{22,23}$ However, as a result, we could not assess glycemia in women in the control group, and thus it is not known whether intensive treatment of gestational diabetes mellitus reduced glycemic levels relative to standard obstetrical care.

The ACHOIS study reported that "serious" perinatal complications were reduced by treatment of gestational diabetes mellitus. The majority of outcomes included in the composite outcome of the ACHOIS trial were cases of shoulder dystocia, which is considered by many to be an intermediate health outcome. ${ }^{8,9}$ Although the primary composite outcome in our trial was not significantly reduced with treatment, the results of our study provide further compelling evidence that among women who have gestational diabetes mellitus and normal fasting glucose levels, treatment that includes dietary intervention and insulin therapy, as necessary, reduces rates of fetal overgrowth, cesarean delivery, and preeclampsia. These findings complement the ongoing analysis of the HAPO study data, which is focused on developing an international consensus for the diagnosis and treatment of carbohydrate intolerance during pregnancy. ${ }^{32}$

\section{Acknowledgments}

Supported by grants from the Eunice Kennedy Shriver National Institute of Child Health and Human Development (HD27915, HD34116, HD40485, HD34208, HD27869, HD40500, HD40560, HD34136, HD 40544, HD27860, HD40545, HD53097, HD21410, HD27917, HD40512, HD53118, HD36801), the General Clinical Research Centers (M01-RR00034), and the National Center for Research Resources (UL1-RR024989, M01-RR00080, UL1-RR025764, C06-RR11234).

We thank Lisa Mele, Sc.M., for protocol management and statistical analysis; Julia Zachary for data management; Francee Johnson, R.N., Joanne Tillinghast, R.N., and Susan Pagliaro for coordination between clinical research centers; Steven G. Gabbe, M.D., and Menachem Miodovnik, M.D., for study design and protocol development; and Roger Newman, M.D., for study design

\section{References}

1. American Diabetes Association. Diagnosis and classification of diabetes mellitus. Diabetes Care 2006;29(Suppl 1):S43-S48. [PubMed: 16373932]

2. Jovanovic L, Pettitt DJ. Gestational diabetes mellitus. JAMA 2001;286:2516-8. [PubMed: 11722247] 
3. O’Sullivan JB, Mahan CM. Criteria for the oral glucose tolerance test in pregnancy. Diabetes 1964;13:278-85. [PubMed: 14166677]

4. Buchanan TA, Kjos SL. Gestational diabetes: risk or myth? J Clin Endocrinol Metab 1999;84:18547. [PubMed: 10372674]

5. Langer O, Yogev Y, Most O, Yexakis EMJ. Gestational diabetes: the consequences of not treating. Am J Obstet Gynecol 2005;192:989-97. [PubMed: 15846171]

6. The HAPO Study Cooperative Research Group. Hyperglycemia and adverse pregnancy outcomes. N Engl J Med 2008;358:1991-2002. [PubMed: 18463375]

7. American College of Obstetricians and Gynecologists. ACOG Practice Bulletin: clinical management guidelines for obstetrician-gynecologists: Number 30, September 2001 (replaces Technical Bulletin Number 200, December 1994): gestational diabetes. Obstet Gynecol 2001;98:525-38. [PubMed: 11547793]

8. Crowther CA, Hiller JE, Moss JR, McPhee AJ, Jeffries WS, Robinson JS. Effect of treatment of gestational diabetes mellitus on pregnancy outcomes. N Engl J Med 2005;352:2477-86. [PubMed: 15951574]

9. Screening for gestational diabetes mellitus: U. S. Preventive Services Task Force recommendation statement. Ann Intern Med 2008;148:759-65. [PubMed: 18490688]

10. Metzger BE, Coustan DR. Summary and recommendations of the Fourth International WorkshopConference on Gestational Diabetes Mellitus. Diabetes Care 1998;21(Suppl 2):B161-B167. [PubMed: 9704245]

11. Lachin JM, Matts JP, Wei LJ. Randomization in clinical trials: conclusions and recommendations. Control Clin Trials 1988;9:365-74. [PubMed: 3203526]

12. American Diabetes Association. Nutrition recommendations and interventions for diabetes: a position statement of the American Diabetes Association. Diabetes Care 2008;31(Suppl 1):S61-S78. [PubMed: 18165339]

13. Moore TR, Piacquadio K. A prospective evaluation of fetal movement screening to reduce the incidence of antepartum fetal death. Am J Obstet Gynecol 1989;160:1075-80. [PubMed: 2729383]

14. Cowett, RM. Hypoglycemia and hyperglycemia in the newborn. In: Polin, RA.; Fox, WW., editors. Fetal and neonatal physiology. Philadelphia: W.B. Saunders; 1992. p. 406

15. Bhutani VK, Johnson L, Sivieri E. Predictive ability of a predischarge hour-specific serum bilirubin for subsequent significant hyperbilirubinemia in healthy term and near-term newborns. Pediatrics 1999;103:6-14. [PubMed: 9917432]

16. Alexander GR, Kogan MD, Himes JH. 1994-1996 U.S. singleton birth weight percentiles for gestational age by race, Hispanic origin, and gender. Matern Child Health J 1999;3:225-31. [PubMed: 10791363]

17. Catalano PM, Thomas AJ, Avallone DA, Amini SM. Anthropometric estimation of body composition. Am J Obstet Gynecol 1995;173:1176-81. [PubMed: 7485315]

18. Gabbe SG, Mestman JG, Freeman RK, Anderson GV, Lowensohn RI. Management and outcome of Class A diabetes mellitus. Am J Obstet Gynecol 1977;127:465-9. [PubMed: 836643]

19. Langer O, Rodriguez DA, Xenakis EM, McFarland MB, Berkus MD, Arredondo F. Intensified versus conventional management of gestational diabetes. Am J Obstet Gynecol 1994;170:1036-46. [PubMed: 8166187]

20. Persson B, Hanson U. Neonatal morbidities in gestational diabetes mellitus. Diabetes Care 1998;21 (Suppl 2):B79-B84. [PubMed: 9704232]

21. Hod M, Merlob P, Friedman S, Schoenfeld A, Ovadia J. Gestational diabetes mellitus: a survey of perinatal complications in the 1980s. Diabetes 1991;40(Suppl 2):74-8. [PubMed: 1748270]

22. Bancroft K, Tuffnell DJ, Mason GC, Rogerson LJ, Mansfield M. A randomised controlled pilot study of management of impaired gestational glucose tolerance. BJOG 2000;107:959-63. [PubMed: 10955425]

23. Garner P, Okun N, Keely E, et al. A randomized controlled trial of stick glycemic control and tertiary level obstetric care versus routine obstetric care in the management of gestational diabetes: a pilot study. Am J Obstet Gynecol 1997;177:190-5. [PubMed: 9240606] 
24. Naylor CD, Sermer M, Chen E, Sykora K. Cesarean delivery in relation to birth weight and gestational glucose tolerance: pathophysiology or practice style? JAMA 1996;275:1165-70. [PubMed: 8609683]

25. Lan KKG, DeMets DL. Discrete sequential boundaries for clinical trials. Biometrika 1983;70:65963.

26. McFarland LV, Raskin M, Daling JR, Benedetti TJ. Erb/Duchenne's palsy: a consequence of fetal macrosomia and method of delivery. Obstet Gynecol 1986;68:784-8. [PubMed: 3785790]

27. Silverman BL, Metzger BE, Cho NH, Loeb CA. Impaired glucose tolerance in adolescent offspring of diabetic mothers: relationship to fetal hyperinsulinism. Diabetes Care 1995;18:611-7. [PubMed: 8585997]

28. Hillier TA, Pedula KL, Schmidt MM, Mullen JA, Charles MA, Pettitt DJ. Childhood obesity and metabolic imprinting: the ongoing effects of maternal hyperglycemia. Diabetes Care 2007;30:228792. [PubMed: 17519427]

29. Brody SC, Harris R, Lohr K. Screening for gestational diabetes: a summary of the evidence for the U.S. Preventive Services Task Force. Obstet Gynecol 2003;101:380-92. [PubMed: 12576264]

30. Cousins, L. Obstetric complications in diabetic pregnancies. In: Reece, EA.; Coustan, DR.; Gabbe, SG., editors. Diabetes in women: adolescence, pregnancy, and menopause. Vol. 3. Philadelphia: Lippincott Williams \& Wilkins; 2004. p. 351-70.

31. Wolf M, Sandler L, Muñoz K, Hsu K, Ecker JL, Thadhani R. First trimester insulin resistance and subsequent preeclampsia: a prospective study. J Clin Endocrinol Metab 2002;87:1563-8. [PubMed: 11932283]

32. Holt RIG. The Hyperglycemia and Adverse Pregnancy Outcomes Trial: answers but still more questions about the management of gestational diabetes. Diabet Med 2008;25:1013-4. [PubMed: 19183304]

\section{APPENDIX}

The other members of the Eunice Kennedy Shriver National Institute of Child Health and Human Development (NICHD) Maternal-Fetal Medicine Units Network are as follows: Ohio State University - J. Iams, F. Johnson, C. Latimer, E. Weinandy, B. Maselli; University of Texas Southwestern Medical Center - K. Leveno, L. Moseley, J. Gold, D. Bradford, L. Fay, M. Garcia; Columbia University - M. Miodovnik, F. Malone, S. Bousleiman, H. Husami, V. Carmona, N. Fredericks, E. Gantioqui, B. Greenspan, M. Williams; University of Utah - K. Anderson (University of Utah Health Sciences Center), P. Ashby (University of Utah Health Sciences Center), S. McAllister (University of Utah Health Sciences Center), S. Quinn (LDS Hospital), A. Guzman (McKay-Dee Hospital), F. Castinella (LDS Hospital), J. Steiner (McKay-Dee Hospital), J. Parker (Utah Valley Regional Medical Center); University of Alabama at Birmingham - J. Sheppard, J. Tisdale, A. Northen, W. Andrews; Brown University - D. Catlow, D. Allard, M. Seebeck, J. Tillinghast, S. Biastre; University of North Carolina - K. Dorman, S. Brody, S. Timlin, J. Bernhardt; Drexel University - M. Hoffman, E. Guzman, M. Talucci, T. Grossman, C. Perez, L. Zeghibe, P. Tabangin; Case Western Reserve University - B. Mercer, B. Stetzer, C. Milluzzi, W. Dalton, S. Pichette; Wake Forest University Health Sciences - M. Swain, P. Meis, J. White; University of Texas Health Science Center at Houston - L. Gilstrap, K. Cannon, J. Martinez, D. Dusek; University of Texas Medical Branch, Galveston - J. Moss, J. Brandon, A. Jackson, G. Hankins, D. Sharp; University of Pittsburgh - S. Caritis, M. Bickus, H. Birkland, M. Cotroneo, N. Cuddy; Wayne State University - G. Norman, P. Lockhart, S. Blackwell; Northwestern University - P. Simon, G. Mallett; Oregon Health and Science University — L. Davis, E. Lairson, C. Cromett, C. Naze, M. Blaser; George Washington University Biostatistics Center - L. Mele, J. Zachary, B. Getachew, C. Cobb, L. Leuchtenburg, S. Gilbert; Eunice Kennedy Shriver National Institute of Child Health and Human Development - S. Pagliaro, K. Howell. 


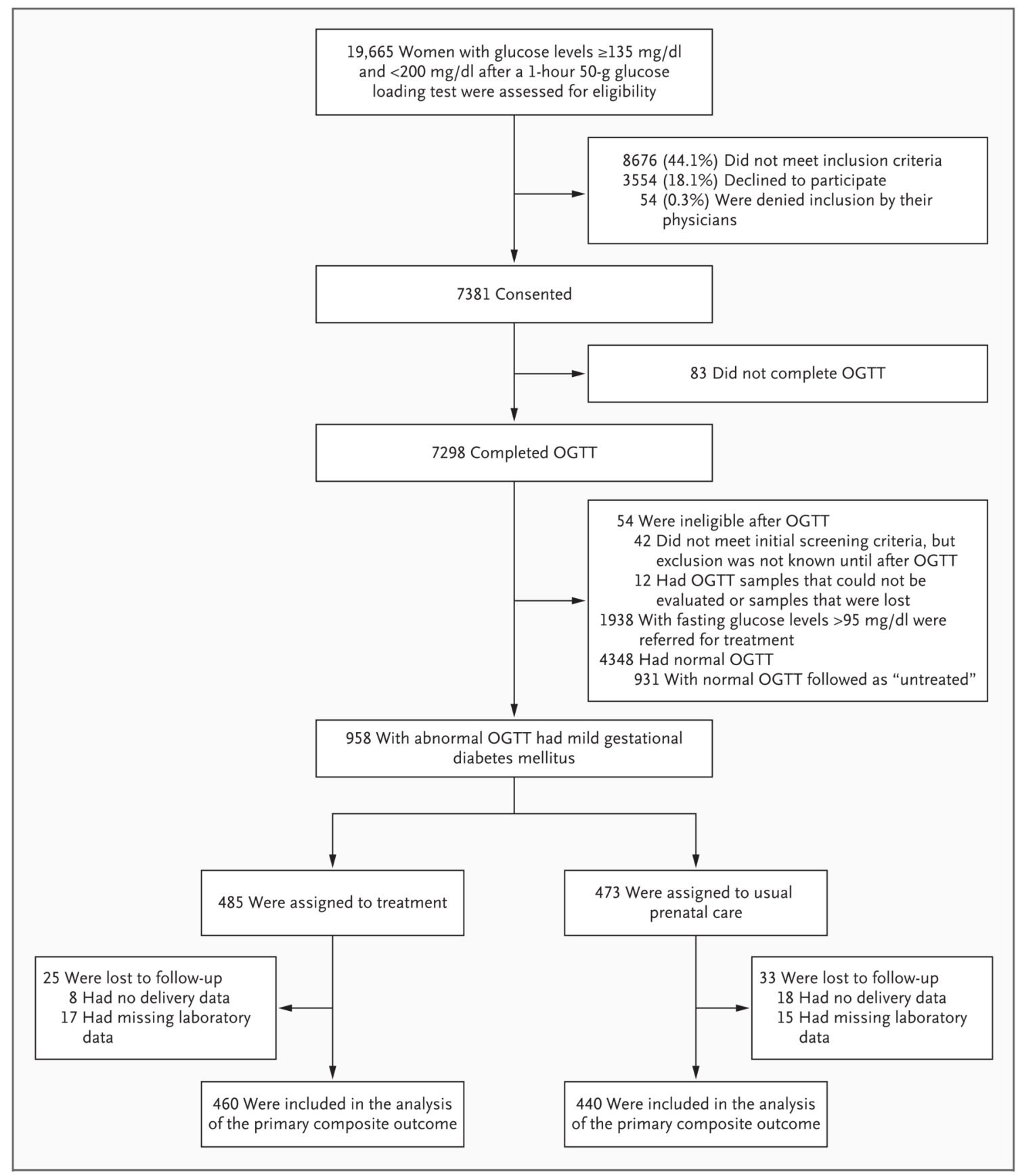

Figure 1. Screening, Enrollment, Random Assignment, and Follow-up of the Study Participants To convert the values for glucose to millimoles per liter, multiply by 0.05551 . OGTT denotes oral glucose-tolerance test. 
Table 1

Characteristics of the Study Population.*

\begin{tabular}{|lcc|}
\hline Variable & Treatment Group $(\mathbf{N}=\mathbf{4 8 5})$ & Control Group (N = 473) \\
Age $-\mathrm{yr}$ & $29.2 \pm 5.7$ & $28.9 \pm 5.6$ \\
Primigravida - no. (\%) & $104(21.4)$ & $123(26.0)$ \\
Race or ethnic group - no. $(\%)^{\dagger}$ & & \\
Black & $56(11.5)$ & $54(11.4)$ \\
White & $123(25.4)$ & $119(25.2)$ \\
Asian & $22(4.5)$ & $28(5.9)$ \\
Hispanic & $281(57.9)$ & $265(56.0)$ \\
Other & $3(0.6)$ & $7(1.5)$ \\
Smoking - no. (\%) & $38(7.8)$ & $31(6.6)$ \\
Alcohol use - no. (\%) & $23(4.7)$ & $11(2.3)$ \\
Body-mass index at entry ${ }^{\ddagger}$ & $30.1 \pm 5.0$ & $30.2 \pm 5.1$ \\
Glucose level after 50-g glucose-loading test - & $159.0 \pm 15.3$ & $159.7 \pm 15.5$ \\
mg/dl & & \\
Duration of gestation randomization - wk & $28.8 \pm 1.6$ & $28.9 \pm 1.5$ \\
Glucose levels in 3-hr OGTT - mg/dl $\$$ & & \\
Fasting & $86.6 \pm 5.7$ & $86.3 \pm 5.7$ \\
1-hr & $191.8 \pm 21.9$ & $193.4 \pm 19.3$ \\
2-hr & $173.7 \pm 21.8$ & $173.3 \pm 19.6$ \\
3-hr & $137.3 \pm 29.0$ & $134.1 \pm 31.5$ \\
\hline
\end{tabular}

* Plus-minus values are means $\pm \mathrm{SD}$. Only alcohol use was significantly different between study groups $(\mathrm{P}=0.04)$. OGTT denotes oral glucose-tolerance test.

${ }^{\dagger}$ Race or ethnic group was self-reported.

The body-mass index is the weight in kilograms divided by the square of the height in meters.

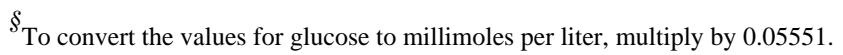


Table 2

Primary Perinatal Outcome.

\begin{tabular}{|c|c|c|c|c|}
\hline Outcome Variable & $\begin{array}{c}\text { Treatment } \\
\text { Group }(N=485)\end{array}$ & $\begin{array}{c}\text { Control Group } \\
(N=473)\end{array}$ & $\begin{array}{c}\text { Relative Risk } \\
\text { (97\% CI) }\end{array}$ & P Value \\
\hline Gestational age at birth - wk & $39.0 \pm 1.8$ & $38.9 \pm 1.8$ & & 0.87 \\
\hline $\begin{array}{l}\text { Composite end point }- \text { no./ } \\
\text { total no. }(\%)^{\dagger}\end{array}$ & $149 / 460(32.4)$ & $163 / 440(37.0)$ & $0.87(0.72-1.07)$ & 0.14 \\
\hline Hypoglycemia & $62 / 381(16.3)$ & $55 / 357(15.4)$ & $1.06(0.73-1.53)$ & 0.75 \\
\hline Hyperbilirubinemia ${ }^{*}$ & $43 / 450(9.6)$ & $54 / 418(12.9)$ & $0.74(0.49-1.12)$ & 0.12 \\
\hline $\begin{array}{l}\text { Elevated cord-blood C- } \\
\text { peptide level }{ }^{+}\end{array}$ & $75 / 423(17.7)$ & $92 / 403(22.8)$ & $0.78(0.57-1.05)$ & 0.07 \\
\hline Stillbirth or neonatal death & 0 & 0 & & \\
\hline Birth trauma ${ }^{\S}$ & $3 / 476(0.6)$ & $6 / 455(1.3)$ & $0.48(0.10-2.20)$ & 0.33 \\
\hline
\end{tabular}

Plus-minus values are means \pm SD.

${ }^{\dagger}$ The composite perinatal outcome included stillbirth, neonatal death, hypoglycemia, hyperbilirubinemia, elevated cord-blood C-peptide level, and birth trauma.

${ }^{+}$

* The results of some blood tests were not available either because samples were not obtained or were not obtained according to protocol or because they could not be assayed owing to a laboratory processing error.

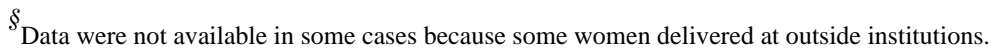


Table 3

Secondary Neonatal Outcomes.*

\begin{tabular}{|c|c|c|c|c|}
\hline Outcome Variable & $\begin{array}{c}\text { Treatment } \\
\text { Group }(N= \\
\mathbf{4 8 5})\end{array}$ & $\begin{array}{l}\text { Control Group } \\
(\mathrm{N}=\mathbf{4 7 3})\end{array}$ & $\begin{array}{l}\text { Relative Risk } \\
\text { (97\% CI) }\end{array}$ & P Value \\
\hline Birth weight $-\mathrm{g}$ & $3302 \pm 502.4$ & $3408 \pm 589.4$ & & $<0.001$ \\
\hline $\begin{array}{l}\text { Birth weight }>4000 \mathrm{~g}-\text { no. } / \\
\text { total no. }(\%)\end{array}$ & 28/477 (5.9) & 65/454 (14.3) & $0.41(0.26-0.66)$ & $<0.001$ \\
\hline $\begin{array}{l}\text { Large for gestational age }- \text { no. } / \\
\text { total no. }(\%)^{\dagger}\end{array}$ & $34 / 477(7.1)$ & 66/454 (14.5) & $0.49(0.32-0.76)$ & $<0.001$ \\
\hline Fat mass $-\mathrm{g}$ & $427.0 \pm 197.9$ & $464.3 \pm 222.3$ & & 0.003 \\
\hline $\begin{array}{l}\text { Preterm delivery — no./total no. } \\
(\%)^{\ddagger}\end{array}$ & 45/477 (9.4) & $53 / 455(11.6)$ & $0.81(0.53-1.23)$ & 0.27 \\
\hline $\begin{array}{l}\text { Small for gestational age }- \text { no./ } \\
\text { total no. }(\%)^{\S}\end{array}$ & $36 / 477(7.5)$ & $29 / 455(6.4)$ & $1.18(0.70-1.99)$ & 0.49 \\
\hline $\begin{array}{l}\text { Admission to NICU - no./total } \\
\text { no. }(\%)\end{array}$ & 43/477 (9.0) & $53 / 455(11.6)$ & $0.77(0.51-1.18)$ & 0.19 \\
\hline $\begin{array}{l}\text { Intravenous glucose treatment } \\
- \text { no./total no. (\%) }\end{array}$ & $25 / 475(5.3)$ & $31 / 455(6.8)$ & $0.77(0.44-1.36)$ & 0.32 \\
\hline $\begin{array}{l}\text { Respiratory distress syndrome } \\
\text { - no./total no. (\%) }\end{array}$ & 9/477 (1.9) & $13 / 455(2.9)$ & $0.66(0.26-1.67)$ & 0.33 \\
\hline
\end{tabular}

* Plus-minus values are means \pm SD. There were 10 women in the treatment group and 19 women in the control group for whom at least some delivery data were missing. NICU denotes neonatal intensive care unit.

${ }^{\dagger}$ Large for gestational age refers to a birth weight above the 90 th percentile.

Freterm delivery refers to delivery before 37 weeks of gestation.

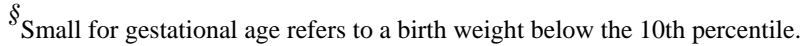




\section{Table 4}

Maternal Outcomes.*

\begin{tabular}{|lcccc|}
\hline Outcome Variable & $\begin{array}{c}\text { Treatment } \\
\text { Group (N=476) }\end{array}$ & $\begin{array}{c}\text { Control Group } \\
\mathbf{( N = 4 5 5 )}\end{array}$ & $\begin{array}{c}\text { Relative Risk (97\% } \\
\text { CI) }\end{array}$ & P Value \\
Induction of labor - no. (\%) & $130(27.3)$ & $122(26.8)$ & $1.02(0.81-1.29)$ & 0.86 \\
Cesarean delivery - no. (\%) & $128(26.9)$ & $154(33.8)$ & $0.79(0.64-0.99)$ & 0.02 \\
Shoulder dystocia - no. (\%) & $7(1.5)$ & $18(4.0)$ & $0.37(0.14-0.97)$ & 0.02 \\
Preeclampsia - no. (\%) & $12(2.5)$ & $25(5.5)$ & $.46(0.22-0.97)$ & 0.02 \\
Preeclampsia or gestational & $41(8.6)$ & $62(13.6)$ & $0.63(0.42-0.96)$ & 0.01 \\
hypertension - no. (\%) & $31.3 \pm 5.2$ & $32.3 \pm 5.2$ & & $<0.001$ \\
Body-mass index at delivery ${ }^{\dagger}$ & $2.8 \pm 4.5$ & $5.0 \pm 3.3$ & & $<0.001$ \\
Weight gain - $\mathrm{kg}^{\dagger}$ & & & & \\
\hline
\end{tabular}

* Plus-minus values are means \pm SD. The number in each group refers to the number of women for whom all delivery data were available.

${ }^{\dagger}$ The body-mass index is the weight in kilograms divided by the square of the height in meters.

${ }^{*}$ Weight gain refers to weight gain from enrollment in the trial until delivery. 
Table 5

Glycemic Values among Women with Gestational Diabetes Mellitus Who Were in the Treatment Group.

\begin{tabular}{|lccc|}
\hline Time of Test & Patients & Median & $\begin{array}{c}\text { Glucose Level } \\
\text { Interquartile Range } \\
\text { mg/dl }\end{array}$ \\
Diet-treated subgroup Fasting & $\boldsymbol{n o .}$ & \multicolumn{2}{c|}{} \\
Fasting & 426 & 80.8 & $(76.4-86.1)$ \\
After breakfast & 427 & 97.3 & $(90.5-104.0)$ \\
After lunch & 427 & 102.6 & $(96.0-109.1)$ \\
After dinner & 427 & 107.8 & $(101.7-115.0)$ \\
Insulin-treated subgroup & & & $(82.9-96.4)$ \\
Fasting & 36 & 90.4 & $(99.1-116.5)$ \\
After breakfast & 36 & 109.7 & $(107.7-121.7)$ \\
After lunch & 36 & 113.2 & $(111.4-128.0)$ \\
After dinner & 36 & 120.6 & \\
\hline
\end{tabular}

* Glycemic values represent available data from memory reflectance meters. The medians and interquartile ranges are for patients' average readings. To convert the values for glucose to millimoles per liter, multiply by 0.05551 . 